\title{
Periferias e ambivalência comunicacional: imaginário e cobertura jornalística sob a mão forte do Estado
}

\author{
Peripheries and communication ambivalence: imaginary \\ and the news covering under the State's strong hand
}

Ada Cristina Machado Silveira Correio

Professora associada III da Universidade Federal de Santa Maria, membro do quadro permanente do PPGComunicação e pesquisadora do CNPq

Resumo: O diálogo entre mídia e imaginário da cultura nacional permite aos processos comunicacionais noticiosos efetivar um controle do poder político sobre amplas camadas sociais periféricas. Uma das características analisadas manifesta-se na armadilha da ambivalência significacional, aspecto fundamental do enquadramento perseguido na cobertura de acontecimentos ocorridos em distintos espaços periféricos brasileiros.

Palavras chave: Periferias; Jornalismo; Imaginário.

Abstract: The dialogue between media and national culture allows news related communicative processes to effect political control over the wide social strata belonging to peripheries. One of the main characteristics analyzed manifests itself by the trap of meaning ambivalence, a fundamental issue of the framing pursued in the coverage of events that take place in different Brazilian peripheral spaces.

Keywords: Peripheries; Journalism; Imaginery. 


\section{Introdução}

O combate ao crime organizado, tomado como Estado paralelo na cidade do Rio de Janeiro, está expondo o comprometimento da mídia nacional para com a ordem legal. Prontamente, o longo convívio social com o tráfico de armas e de drogas, máfias do jogo de bicho, caça-níqueis, bingos e prostituição foi desbancado em favor da aprovação pelo que se denominou de "penetração das forças legais".

A cobertura dos acontecimentos da periferia metropolitana articula um diálogo entre noçóes provenientes do noticiário midiático e do imaginário da cultura nacional com foco nas relaçóes entre sociabilidade urbana e segurança pública. ${ }^{1}$ A aprovação da intervenção das forças armadas em conjunto com os contingentes policiais nos eventos genericamente identificados como "de pacificação", ocorridos a partir de novembro de 2008 legitimou a mídia de referência no trabalho de alimentar seu projeto noticioso. Entretanto, ao analisar a relação existente entre tais práticas noticiosas e aquelas atinentes à cobertura das fronteiras internacionais brasileiras, um profundo questionamento é passível de ser feito. Ele consiste em apontar que as periferias metropolitanas, obviadas em sua concretude e contexto histórico, são alinhadas a outras periferias, como aquelas localizadas nas fronteiras internacionais. A homologia produzida entre fronteiras e favelas induz à ambivalência comunicacional, cujas consequências são em parte aqui analisadas. Uma delas consiste em reconhecer que a atividade comunicacional noticiosa, ao sustentar um determinado projeto para sua comunidade imaginada, supóe que submeter populaçóes às penas da lei, visando adequá-las à ordem, ignora o preço de submetê-las a outro ordenamento, o do mercado internacional de fluxos e bens de consumo. Ao pretender salvá-las do gueto e do isolamento, assegurando sua vinculação e interdependência com a comunidade nacional, também induz a submeter-se a outras ordens que articulam outros vínculos entre controle do imaginário e controle do real. Novas articulaçôes que, no entanto, não podem prescindir do simbólico.

$\mathrm{O}$ artigo apresenta alguns elementos considerados pertinentes à reflexão sobre a articulação entre a ação social da mídia e sua incidência no controle do imaginário. Nossa análise do fenômeno noticioso enquadra-se no panorama da crítica cultural contemporânea. Conforme essa abordagem, registramos em trabalhos anteriores nosso entendimento de que a conversão em notícia de acontecimentos ocorridos em periferias observa um enquadramento ambivalente que as toma genericamente como um outro marcado pela ânsia de expansão do projeto moderno. As apropriações do outro na cobertura jornalística tomadas como vicárias do projeto moderno têm no imaginário sobre as periferias um caso arquetípico. Apontamos o tratamento das periferias como refugo social, "casos exemplares da cobertura de territórios sem diálogo, seja ele da sociedade com seus problemas ou da sociedade com suas autoridades, seja da mídia com a sociedade. $\mathrm{O}$ veredito de violência já está estabelecido para

\footnotetext{
${ }^{1}$ Em Between Women: Domestics and Their Employers, Rollins propóe o termo maternalismo em vez de paternalismo para justificar a subserviência dos criados nestas relaçóes assimétricas (Brites, 2008).
} 
acontecimentos atravessados pela perspectiva periférica, contém notoriedade e faz-se passível de noticiabilidade obrigatoriamente" (SILVEIRA, 2009, p. 163). ${ }^{2}$

Recuperando aspectos de estudos empíricos do tema, recordamos a análise de três corpora. Criados a partir de ediçóes dos anos 2006-2007 de um diário fronteiriço (A Gazeta do Iguaçu), conforme registramos em Silveira (2012, p.78), “em contraste com a análise de dois semanários nacionais no mesmo período (Época e IstoÉ), [o comparativo dos corpora] aponta a consistência da hipótese de que o agenciamento jornalístico mantém a noticiabilidade sobre as periferias numa condição discursiva ambígua e que responde por seu enquadramento como alarmes de incêndio, convertendo-as em patrimônio territorial do Estado-nação". 3

O conjunto de estudos empíricos aqui brevemente referidos propiciaram as reflexóes que apontamos a seguir. Iniciamos por aspectos que se detém na positividade do controle encetada pela mídia.

\section{A positividade do controle do imaginário}

A mídia, ao produzir noticiários, engolfa diversos e heterogêneos mundos, subsumidos em favor da mediação do nacional e na sua construção histórica, social, política e mesmo econômica. Trata-se de uma atividade na qual heterogeneidades estruturais devem ser de algum modo elididas no sentido de favorecer a construção da identidade nacional. Valores deficitários têm no imaginário periférico um material imperecível, com propriedades que permitem que eles sejam permanentemente recordados.

A positividade de um controle do imaginário envolve considerar que o enquadramento violento e criminoso perseguido nas coberturas não é gratuito. Alimentado pelos altos índices de mortandade de jovens em metrópoles, o jornalismo adicionou-lhe realidades fronteiriças, as quais gozam da denominação geopolítica de "especiais" às problemáticas recorrentes de violência e criminalidade. No caso da primeira, os indiscutíveis índices de violência conduzem, no entanto, a uma articulação mecânica de realidades que não estão tão tranquilamente vinculadas como, à primeira vista, se propóe.

Para nos aproximarmos do nível local a um dos mais expressivos espaços periféricos do Brasil, localizado na tríplice fronteira Brasil-Paraguai-Argentina, recorrendo a um dos diários de Foz do Iguaçu-PR. O município é atualmente expressão do adensamento populacional fronteiriço que a região Sul conhece desde os tempos da colonização. Um território humanizado com lutas e

\footnotetext{
${ }^{2}$ Nossa abordagem de crítica cultural do jornalismo encontra paralelo na proposta de Vaz, Sá Carvalho e Pombo (2005, p.22), quando postulam a "renovação da gramática crítica com a inclusão da construção midiática da idéia de sofrimento evitável".

${ }^{3}$ No artigo registramos que a revista Época publicou quase que o dobro de matérias (88) comparada à revista IstoÉ (41), identificadas pelos marcadores discursivos "periferia, fronteira, favela", bem como os marcadores "contextual periferia/favela" e "periferia fronteira".
} 
batalhas militares cujas narrativas já celebraram e, hoje, são atualizadas em matérias como a que leva por título "Tiroteio na ponte". Nela, a repórter local destaca que "O ataque aos cerca de 3,5 mil sacoleiros que se aglomeravam na região da ponte começou por volta das $9 \mathrm{~h} 50$. Às $10 \mathrm{~h} 30$ os disparos, um dos confrontos mais longos da história da fronteira, continuavam na região da Vila Pontes e Jardim Jupira” (Gazeta do Iguaçu, 17/03/2006, on line).

Como esse exemplo, os acontecimentos ocorridos nas periferias ganham as manchetes com frequência, o que é feito com base em índices de violência, considerados fatos iniludíveis da realidade. Fruto dessa relação, a cobertura jornalística necessita das periferias e as considera como fonte permanente de material noticiável, instituindo-a no sentido apanhado por Castoriadis: "A instituição da sociedade pela sociedade instituinte apoia-se no primeiro estrato natural do dado - e encontra-se sempre (até um ponto de origem insondável) numa relação de recepção/alteração com o que já tinha sido instituído" (CASTORIADIS, 1986, p. 414).

Os autores do noticiário, de seu lado, argumentam que ainda que a capacidade do discurso jornalístico de exercer sua prática mimética sobre a realidade possa ser discutível, os números de jovens mortos por homicídio são reais e não podem ser banalizados ou reduzidos.

A esse respeito, Julio J. Waiselfisz (2010, p. 125) apresenta um mapa da violência, no qual se destaca que os dados sobre a violência homicida têm colocado o Brasil em sexto lugar no ranking internacional da taxa de homicídios de jovens entre 15 e 24 anos (WAISELFISZ, 2010, p. 87). Ademais, sustenta o pesquisador, "Se, em 1997, 42,6\% dos homicídios do país aconteciam nas capitais, essa proporção cai rapidamente para, em 2007, representar 34,6\%. Isto é, um ritmo de queda perto de $1 \%$ ao ano". No entanto, o lócus privilegiado da violência homicida permanece nas regiōes metropolitanas. Ele analisa ainda: "Municípios de pequeno e médio porte que, por sua localização de fronteira internacional, institucionalizam fluxos de elevada violência potencial, como grandes organizaçóes de contrabando de produtos ou armas, pirataria e tráfico de drogas" (WAISELFISZ, 2010, p.131).

Nesse contexto, os números de Foz do Iguaçu-PR colocam o município em destaque, chegando ao primeiro lugar no Brasil com a mais alta taxa de homicídios na população entre 15 e 24 anos (id. ibid., p. 79).

Diante do quadro alarmante sobre os indicadores de violência nas periferias, estabelecer um vínculo entre homicídios de jovens e sua condição de moradores frente ao noticiário requer recuperar um histórico que extrapola nosso objetivo aqui. No entanto, por mais cabais que sejam os números, a cadeia de significantes suposta na vinculação de realidades de formação socio-histórica tão distintas entre si exige mais atenção que as identidades generificadas reproduzidas em larga escala. Nosso propósito é apontar como a produção de 
noticiário se move num vácuo onde há cada vez mais incomunicação entre processos que operam no nível local, regional, nacional e internacional.

Gozam de privilégio nesse noticiário as decisôes de política econômica, especialmente os aspectos atinentes à proteção, como subsídios, barreiras alfandegárias, licenças, quotas e todo tipo de barreiras ao comércio internacional. E assim ganha protagonismo a liminaridade a que se submetem temporariamente os muambeiros, sacoleiros, laranjas e todo tipo de trabalhadores informais que como novos mercadores cruzam o Brasil e suas fronteiras com países vizinhos em busca de sobrevivência. É importante destacar que são as assimetrias regionais que ativam todo tipo de circulação e elas são subjugadas ao projeto maior de construção da nacionalidade, para o qual se faz legítimo reduzi-las a trocas ilícitas.

O efeito polarizador decorrente da incriminação constante de certas atividades produtivas, distinguindo legais de ilegais, atinge especialmente aos trabalhadores da atividade comercial. A mídia apresenta seu noticiário com a seriedade que lhe concerne ao se ter como grande mediadora de relaçóes sociais, dotada da propriedade de informar, sintetizar e mobilizar para projetos sociais, animando a produção de consensos duradouros. No entanto, conforme analisamos a seguir, é possível sustentar também o seu oposto.

\section{Periferias e esconjurações $X$ narrativas e fronteiras culturais}

As ponderaçôes anteriormente expostas requerem considerar que passamos de lógicas de representação de identidades para lógicas de identificação, nas quais a mídia opera através da inculcação de imagens que refletem não a unidade de cada sujeito, mas sua singularidade. A identidade cristaliza-se e estabelece como referência o ser; enquanto que um processo de identificação dá ênfase ao expressar. Recorrendo novamente a Castoriadis, o imaginário consistiria, portanto, na capacidade de formar imagens e, igualmente, no efeito alienante da identificação com elas.

O noticiário produzido sob o efeito dos controles do Estado e da ordem legal conduz ao constrangimento e enfraquecimento de uma concepção de imaginário policêntrica. Esmagada sob o peso do Estado e pela opressão da centralidade, a ambivalência significacional imperante nas narrativas sobre periferias produz repercussôes discursivas em realidades tâo distintas quanto podem ser os processos de segurança pública como foi comentado. Ou ainda, em processos individuais de identificação e reconhecimento de si ou mesmo as relações internacionais. A ambivalência opera assim na construção de um noticiário de alcance nacional através de eventos locais reconfigurados pela lógica de mercado que incide globalmente.

Ao constatar que a globalização atinge de modo muito distinto a ricos e pobres (Bauman, 1999), produzir narrativas discriminatórias pode configurar uma forma a mais de exclusão. A exclusão discursiva está presente numa declaração que dá ideia da repercussão tanto dos indivíduos como das relaçôes 
internacionais, depreendida das palavras do presidente boliviano: "Así que ahora somos narcoterroristas", e continuou Evo Morales: "Cuando no pudieron seguir llamándonos comunistas, nos llamaron subversivos, y después traficantes, y terroristas desde los ataques del 11 de septiembre", para concluir: "la historia de América Latina se repite."

Como, então, se sustenta socialmente um noticiário que descarrega cotidianamente baterias de acusaçóes?

Ao produzir um efeito de sentido que inferioriza moralmente as populaçôes evocadas, o noticiário está ludibriando uma das raízes da problemática dessas acusaçôes. Essa raiz advém do propósito de produzir-se um noticiário de âmbito nacional por pessoas que vivem localmente e que tratam de problemas de agentes que transitam globalmente. Alguns agentes são constituídos de carne e osso por pessoas, a maioria migrantes, ou descendentes de migrantes que se deslocam continuamente, seja pelo espaço metropolitano, seja esporadicamente pelo interior do território nacional e internacional. A passagem que responde pelo tratamento de problemas de trabalhadores informais e outros agentes, via rótulo comum de crimes de descaminho e contra a ordem tributária, é um processo obscuro e muitas vezes compreendido linearmente. Como uma parcela da população pobre tem o esforço de seu trabalho confrontado com a ordem legal? Ou, mais que isso, como o noticiário se nutre de acontecimentos que produzem um claro embate com o imaginário sem nenhum caráter de Macunaíma?

Enquanto o jornalismo faz um permanente julgamento moral dos crimes de descaminho e contra a ordem tributária, reiterando a estigmatizaçáo das sociedades periféricas, os relatos de ficção deslumbram com um mundo de maravilhas, como é o suprimento de minisséries em TV aberta. Novamente retornamos ao impasse entre os sinais trocados atuando no nível da identidade coletiva que recebe aluvióes de mensagens contraditórias. Niklas Luhmann (2000) comenta que os meios de comunicação ao disporem em sua grade de programaçáo tanto do jornalismo, como do entretenimento e da publicidade, dificultam a análise da repercussão de suas práticas.

$\mathrm{Na}$ publicidade, a diversidade aparece especialmente na promoção da identidade cultural, com produtos que buscam emocionar ao evocar as idiossincrasias da sociabilidade (as sandálias havaianas), a diversidade e o localismo. Estes são amplamente explorados pelo marketing, especialmente nas situaçóes de expansão de redes de supermercados, lojas de eletroeletrônicos e, principalmente, companhias telefônicas.

A crítica cultural da mídia permite avaliar que há um contrato em que podem ser distinguidas duas dinâmicas narrativas, uma apegada ao nível factual e outra alinhada com o nível ficcional/entretenimento:

- a factual atua nas práticas do noticiário e implica em preceitos como: correção dos limites, imputação do desvio, condenação da liminaridade, 
prescriçóes morais para os envolvidos e vigência da ordem heterônoma em sobreposição aos indivíduos.

- a ficcional/entretenimento atua na produção audiovisual de telesseries e cinematografia, tanto quanto na cobertura de futebol e esportes em geral, e implica num projeto articulado com as forças da globalização e com a autonomia dos indivíduos.

A incidência do imaginário midiático sobre outros imaginários com o advento da globalização necessita da crítica cultural da mídia, especialmente da análise do fenômeno comunicacional noticioso. O reconhecimento de novas situaçôes como a multiplicidade dos entre lugares produzidos pelo periférico, tomados como in-between de que fala Hommi Bhabha (1998), finalmente são postos a descoberto. Evidencia-se o jornalismo sustentando os conceitos de unidade e de pureza, na contramão de todo esforço cultural latino-americano inclinado a promover as narrativas sobre nossas fortes fronteiras culturais. Trata-se de um aspecto que expóe a negatividade dos controles.

\section{A negatividade do controle do imaginário}

A negatividade do controle ocorre quando sua força de disciplina é utilizada em favor do próprio agente, ou seja, a mídia quando produz seu noticiário e desconsidera a multiplicidade de perspectivas da sociedade.

Como pensar a negatividade do controle que a mídia pode ter sobre o imaginário? Qual é o contrato que preside essas relaçôes?

Quando se alerta para os aspectos negativos do controle do imaginário o que temos em vista é a insistência com que o noticiário se pauta por valores que expóem aspectos ambivalentes próprios da condição liminar que este início de globalização proporciona, bem como a ambivalência de espaços periféricos urbanos que não contam com a presença do Estado, a não ser na forma das forças de repressão. Exaltam-se nesta tarefa consagrados âncoras televisivos com seus bordôes herdeiros do sumário "mato, prendo e arrebento".

Neste aspecto, é exemplar a iteração que a negação do controle do imaginário provou com uma matéria que foi destaque num semanário brasileiro. Um Delegado da Polícia Federal sentenciou que na tríplice fronteira BrasilPeru-Colômbia "quem não traficou um dia traficará". Oportunistamente, o semanário valeu-se da fronteira como foco de conflito. No entanto, a matéria provocou reaçóes numa populaçáo residente a mais de 5.480 quilômetros de onde se fez eco a declaração do agente local. Na semana seguinte, outro semanário nacional lhe deu a suíte apresentando aquilo que Habermas denominou de "a vingança do objeto". A Fig. 1 reproduz a matéria que cobre a manifestação pública dos moradores: 
Fig.1 - Reação em Tabatinga

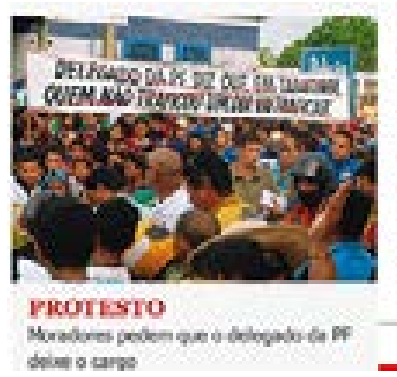

\section{7-TABATINGA (AM)}

'Qvem nlo traticou un dia val traflar'

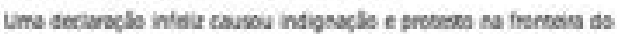

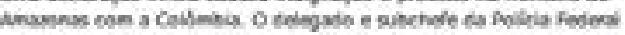

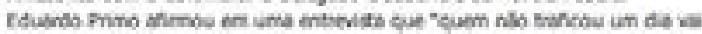

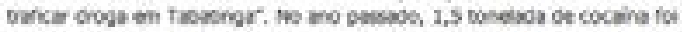

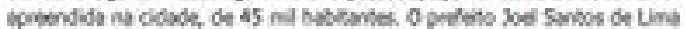

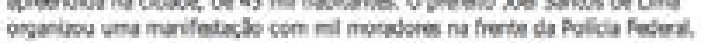

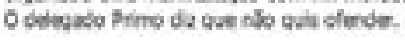

Fonte: Revista Época, 23/07/08.

Conforme a matéria da revista Época, os moradores do município fronteiriço ressentidos com a manifestação da autoridade policial, promoveram uma manifestação. Tabatinga, município no estado do Amazonas, situa-se na fronteira do Brasil com a Colômbia (Leticia) e com um povoado peruano de Villa de Santa Rosa. Sua representação identitária sofre contínuos bombardeios ao ser vinculada ao tráfico de droga e de armas. O exemplo registra este padrão de insultos infligidos à população local. O Delegado da Polícia Federal argumentou frente ao alcance de suas palavras e o protesto dos locais que não pretendia ofender. Elas o integram no contingente de pessoas que alimentam a tendência de opiniáo à deriva do alcance global de acontecimentos locais. Já o grupo de mídia pode referendar o mandato de informar com isenção frente ao factualismo episódico, responsável pelo enquadramento como corredor internacional de distribuição de cocaína e armas, bem como sua antiga ligação com as Forças Armadas Revolucionárias Colombianas (FARCs).

Mídia, Polícia Federal e tantos outros são agentes de uma transição que se situa ainda no começo da globalização. No entanto, seu imaginário está formado num Brasil enclausurado, com vocação para a introversão num território de dimensões continentais.

A cobertura jornalística projeta luz e sombra permanente sobre as periferias, alimentando uma indistinção reificante. Ela se legitima quando ilumina estruturas corruptas, mas ao mesmo tempo lança sombras sobre possíveis antinomias existentes nos mesmos domínios. Assim, promove uma indiferenciação que impede a autonomia daquelas sociedades, atrelando-as a uma lógica centralizadora que alimenta o imaginário sobre um amplo território sertanejo situado entre a linha de fronteira brasileira e suas metrópoles litorâneas a mero corredor de armas e drogas. Analisamos qual a importância de perseguir uma linha editorial pautada por esse princípio e a quais valores e interesses ela se presta. 


\section{O agenciamento jornalístico e a produção da uniformidade}

Algumas marcas discursivas indicadoras da positividade do controle podem ser buscadas no noticiário local das periferias e aditam a tarefa de construir narrativas em situaçóes de fronteira cultural. É o caso de sucessivas reportagens sobre a questão da assistência de saúde a brasiguaios e todo tipo de acordos que buscam estabelecer competências locais para políticas entre Estados, conforme expóe a Fig. 2:

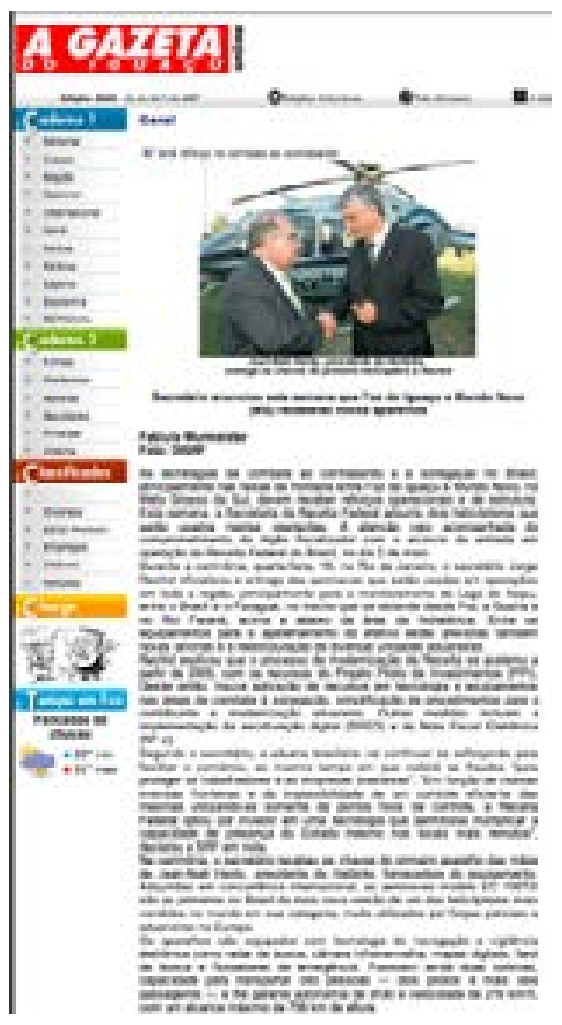

Fig.2 Acordos locais-internacionais

Fonte: A Gazeta do Iguaçu, 28/04/2007.

O privilégio do factual, passível de ser examinado e constatado visa regular sistematicamente a realidade periférica e amparar a atividade de agentes.

Assim, não se faz de todo precoce a hipótese de que a imprensa de larga escala e a TV aberta trabalhem para informar pessoas que circulam localmente, enquanto os diários locais das cidades fronteiriças se antecipam, provando aquilo que as mídias segmentadas já descobriram: o filão das pessoas que transitam inter regionalmente, internacionalmente ou globalmente. Trata-se de desvelar um percurso no qual o imaginário local é desapropriado em favor do imaginário midiático e, este, por sua vez, o devolve sob a forma de uma cobertura jornalística de acontecimentos reconfigurados pela lógica de mercado. $\mathrm{O}$ imaginário midiático ao atuar como mediador de vários níveis (local, nacional, 
etc.) estabelece um diálogo com outros imaginários evidenciando um "acoplamento mínimo de significante-significado” (SRINIVASAN, 2002, p. 77) e hierarquizando os valores de uma época.

O paradigma centro-periferia e especialmente a teoria da dependência foram promovidos no Brasil durante a segunda metade do século XX com vistas a explicar muitos fenômenos além da ordem do econômico. $\mathrm{O}$ termo periferia foi na época utilizado para designar espaços desintegrados do eixo dominante ao nível planetário e, mais adiante, transferido, mimeticamente, para o interior da nação. Em defesa de uma perspectiva brasileira do problema, Roberto DaMatta pondera sobre a questão da ambivalência:

\footnotetext{
Como ter horror ao intermediário e ao misturado, se pontos críticos de nossa sociabilidade são constituídos por tipos liminares como o mulato, o cafuzo e o mameluco (no nosso sistema de classificação racial); o despachante (no sistema burocrático); a(o) amante (no sistema amoroso); o(a) santo(a), o orixá, o "espírito" e o purgatório (no sistema religioso); a reza, o pedido, a cantada, a música popular, a serenata (no sistema de mediação que permeia o cotidiano); a varanda, o quintal, a praça, o adro e a praia (no sistema espacial); o "jeitinho", o "sabe com quem está falando?" e o "pistoláo" (nos modos de lidar com o conflito engendrado pelo encontro de leis impessoais com o prestígio e o poder pessoal); a feijoada, a peixada e o cozido, comidas rigorosamente intermediárias (entre o sólido e o líquido) no sistema culinário; a bolina e a "sacanagem" (no sistema sexual). Isso para não falar das celebridades inter, trans, homo ou pansexuais, que, entre nós, não são objeto de horror ou abominação (como ocorre nos Estados Unidos), mas de desejo, curiosidade, fascinação e admiração. Tudo isto me levou a repensar o ambíguo como um estado axiomaticamente negativo (DA MATTA, 2000, p.14).
}

A segregação midiática das periferias corresponderia socialmente ao que os ritos de passagem significam ao nível pessoal; através deles as práticas perderiam a compartimentalização e autonomia com vistas à adequação e enquadramento a valores ditados pela ordem legal. Em outras palavras, seria o contraste entre acontecimentos particulares frente a uma pretensa normalidade vigente num centro tomado como alegoria nacional que engendraria a liminaridade das periferias.

Pensamos assim comprovar como é que se opera a exclusão das favelas do contexto urbano - que a circunda e/ou a permeia - em favor da promoçáo de um centro depurado de ambiguidades classificatórias, o que ocorre através da imposição de leis impessoais. No entanto, é paradoxal observar que para a população local a violência não está obrigatoriamente associada a situaçôes que 
desclassificam socialmente seus indivíduos conforme postula a ordem legal. Recorde-se que nunca um imaginário se reduz a um conjunto de regras impessoais. O limem invocado pelo agenciamento jornalístico não é legitimado tão facilmente pela sociedade brasileira. Ao contrário, ela nutre grande simpatia por situaçóes ambíguas, como exemplifica DaMatta (2000) ao recordar de nosso forte convívio com a ambiguidade.

\section{Os julgamentos morais e a segregação midiática}

Para a produçáo de uma cobertura que considere a alteridade, apontamos que um problema central da mentalidade vigente na cobertura analisada é o de que ela trai a ideia de um Brasil possível.

O imaginário do circuito noticioso analisado ainda não foi afetado pela nascente cultura urbana fruto da globalização, na qual o reconhecimento do outro em sua alteridade, a distância e a heterogeneidade estáo sendo incorporadas. A realidade de apontar o caráter delinquente dos indivíduos é uma atribuição generalizante que aponta mais para a dificuldade de compreensão de novas situaçóes do que propriamente para atitudes enquadradas criminalmente e que, bastando uma mudança de legislação, poderão ter outro tratamento: "O imaginário social ou a sociedade instituinte é na e pela posição-criação de significações imaginárias sociais e da instituição; da instituição como "presentificação" destas significações e destas significações como instituídas" (CASTORIADIS, 1986, p. 414) (grifos do autor).

A reflexão resultante da investigação em parte relatada aqui conduz ao uso que a cobertura jornalística faz dos acontecimentos periféricos enquanto artifício próprio da ritualidade nacionalista centralizadora, alimentando o que Fredric Jameson (1995) denomina de "alegoria nacional" como característica da narratividade do Terceiro Mundo. As fraturas no projeto de cobertura da realidade nacional não resistem aos entrelugares que se inauguram quando a noção de Estado nacional entra em crise. Entender que há um processo de desestabilização do centro é fundamental na atual ordem globalizadora hegemônica. E o valor que o conhecimento do contexto significacional traz ao debate permite esclarecer sua centralidade no presente momento em que lógicas culturais se debatem, tanto quanto as lógicas econômicas. Aí se começa a compreender porque os relatos sobre os agentes que estão em negociação não podem se reduzir à criminalização daqueles que a nação previamente excluiu da escola formal, do mercado de trabalho formal e que a ordem global tornou muambeiros.

Apresenta-se como subjacente a tarefa de avaliar o valor da descentralização do Estado e a reconsideração de sua presença múltipla através do agenciamento midiático. É importante encarar a questão de qual o sentido de manter 
narrativas que sustentam um comportamento desagregador que contrapóe o Estado legal à sociedade local?

Trata-se de um contexto no qual se confirma como é que a emergência da hybris no imaginário nacional se faz em evidente ameaça à vigência de velhas alegorias nacionais, de resto tão convenientes para atrair turistas estrangeiros. E daí a necessidade de esconjurar suas ultrajantes representaçóes midiáticas magnificadas pela vivência periférica.

Nossa análise buscou demonstrar como o imaginário nacional e sua apropriação pela atualização midiática encontram-se atrelados ao interesse das instituiçôes ligadas ao Estado. A que ordem este fenômeno se vincula? Estranhamente, ela ainda se orienta pelos ditames da Guerra Fria que fomentou no Brasil a Ideologia da Segurança Nacional.

Os tentáculos de um Estado autoritário aparecem na atividade jornalística de maneira indisfarçável e os guardiôes da liberdade de imprensa não possuem pruridos ao enquadrar sistematicamente fronteiras e favelas por acontecimentos criminais. Reitera-se o confinamento discursivo face à incapacidade de encarar a riqueza polissêmica que as periferias sempre representaram e com a qual ameaçam qualquer propósito de construção de múltiplas identidades nacionais.

É da Modernidade o feito da ambivalência significacional resolver problemas acarretados pelo cenário emergente no qual se produz a segregaçáo daqueles que transitam globalmente em situação liminar ao mesmo tempo em que a mídia celebra superficialmente imaginários plenos das novas facilidades. Qual o obstáculo para a instauração de algum traço imaginário radical que permita um diálogo entre a sociedade instituinte e a sociedade por ela instituída?

Desse diálogo ressalta-se a proclama de Alceu Valença: "Quando eu canto/o seu coração se abala/pois eu sou/porta voz da incoerência”. E assim, o jornalismo sob o peso do Estado debate-se num projeto que oscila entre o material híbrido das narrativas locais e o hieratismo de certo projeto global, verticalizador e ascético frente às necessidades correntes da vida social.

A ambivalência discursiva guarda em potência ingredientes fundamentais para realizar o mais caro ao projeto brasileiro de nação: o de forjar uma identidade nacional imune às diferenças, capaz de atualizar a consistência unitarista que o mito das três raças forjou. Mas isto será feito no embate com o mito/discurso de pertencimento ao Estado múltiplo, para o qual concorrem tantas criaçôes atualmente tomadas pelo noticiário como manifestos de antibrasilidade. 


\section{Referências bibliográficas}

BHABHA, H. O local da cultura. Belo Horizonte: UFMG, 1998.

BAUMAN, Z. Globalização: as conseqüências humanas. Rio de Janeiro: Zahar, 1999.

CASTORIADIS, C. A instituição imaginária da sociedade. Rio de janeiro: Paz e Terra, 1986.

DAMATTA, R. Individualidade e liminaridade. Maná. n.6. v.I. p.7-29, 2000.

JAMESON, F. Espaço e imagem. Rio de Janeiro: UFRJ, 1995.

LUHMAN, N. The reality of mass media. Londres: Polity Press, 2000.

MAFFESOLI, Michel. A contemplação do mundo. Porto Alegre: Artes e Ofícios, 1995.

SILVEIRA, Ada C. M. da. Modos de ver e devorar o outro. Ghrebh, São Paulo, out., n.14, 2009, p. 157-176.

A cobertura jornalística de fronteiriços e favelados-narrativas securitárias e imunização contra a diferença. Intercom, São Paulo, v.35, n.1, jan./ jun.2012. p.75-92.

SRINIVASAN, S. K. Castoriadis, Cornelius (1922-1997). In: PAYNE, M. (comp.) Diccionario de teoría crítica y estudios culturales. Barcelona: Paidós, 2002. p.77-8.

SHOHAT, E., STHAM, R. Rethink eurocentrism. Londres/Nova Iorque: Routledge, 1994.

WAISELFISZ, J. J. Mapa da violência 2010: anatomia dos homicídios no Brasil. São Paulo: Instituto Sangari, 2010.

VAZ, Paulo; SÁ-CARVALHO, Carolina; POMBO, Mariana. Risco e sofrimento evitável: a imagem da polícia no noticiário de crime. e-compós (on line), dez. 2005, 22 p.

\section{Periódicos}

A Gazeta do Iguaçu, 17/03/2006. Disponível em: "http://www.gazeta.inf.br/" Acesso em 02/07/2010.

A Gazeta do Iguaçu, 30/05/2006. Disponível em: "http://www.gazeta.inf.br/" Acesso em 02/07/2010.

A Gazeta do Iguaçu, 13/06/2006. Disponível em: "http://www.gazeta.inf.br/" Acesso em 02/07/2010. 
A Gazeta do Iguaçu, 22/06/2006. Disponível em: "http://www.gazeta.inf.br/" Acesso em 02/07/2010.

A Gazeta do Iguaçu, 08/07/2007. Disponível em: "http://www.gazeta.inf.br/" Acesso em 02/07/2010.

A Gazeta do Iguaçu, 28/04/2007. Disponível em: "http://www.gazeta.inf.br/" Acesso em 05/08/2010.

Revista Época, 23/07/08 e atualizada em 16/04/2009. Disponível em: "http://revistaepoca.globo.com/ Revista/Epoca/0,EMI6102915215,00-FALA+BRASIL.html” http://revistaepoca.globo.com/ Revista/ Epoca/0,EMI61029-15215,00-FALA+BRASIL.html. Acesso em 20/06/2009. 